\title{
АЦИЛГОМОСЕРИНЛАКТОНЫ КАК РЕГУЛЯТОРЫ УРОЖАЙНОСТИ И СТРЕССОУСТОЙЧИВОСТИ СЕЛЬСКОХОЗЯЙСТВЕННЫХ КУЛЬТУР* \\ (обзор)
}

\author{
Л.М. БАБЕНКО ${ }^{\circledR}$, Е.А. РОМАНЕНКО 1 , О.С. ЮНГИН ${ }^{2,} 3$, \\ И.В. КОСАКОВСКАЯ1
}

Ацилгомосеринлактоны (АГЛ) - класс молекул медиаторов, координирующих активность клеток в популяции грамотрицательных бактерий. АГЛ синхронизируют индивидуальные клеточные геномы, благодаря чему бактериальная популяция функционирует как многоклеточный организм. Они обеспечивают дистанционный сигналинг между бактериями - колонизаторами фитосферы, что позволяет популяции реагировать на внешний сигналинг и устанавливать симбиотические либо антагонистические отношения с растением-хозяином (A.R. Stacy с соавт., 2018; A. Shrestha с соавт., 2020). Ауторецепция количественных параметров бактериальной популяции называется «quorum sensing» (QS) (R.G. Abisado с соавт., 2018). QS-системы образуют сигнальные молекулы аутоиндукторы, легко проникающие из клеток в окружающую среду и обратно в клетку (M.B. Miller с соавт., 2001; B. Bassler, 2002). Системам QS принадлежит ключевая роль в регуляции метаболических и физиологических процессов, происходящих в бактериальной клетке (M. Frederix c coaвт., 2011; M. Whiteley с соавт., 2017). Бактериальный сигналинг воспринимается эукариотами, которые образуют симбиоз с микробными сообществами (S.T. Schenk с coaвт., 2015; Л.М. Бабенко с соавт., 2016, 2017). Рост и развитие растения, ассимиляция питательных веществ, стрессоустойчивость во многом определяются характером такого взаимодействия (Н.Р. Ваis с соавт., 2006; R. Ortíz-Castro с соавт., 2009; S. Basu с соавт., 2017). Управлять бактериальным сигналингом растению позволяет система «quorum quenching» (QQ) (N. Calatrava-Morales с coaвT., 2018), механизм действия которой состоит в подавлении растительными метаболитами синтеза АГЛ, конкуренции с АГЛ за связывание с рецепторными белками, репрессии QS-контролируемых генов (H. Zhu с соавт., 2008; R. Sarkar с соавт., 2015). Однако в настоящее время молекулярные механизмы, с помощью которых растения реагируют на бактериальный сигналинг, до конца не выяснены. Часть метаболитов АГЛ-сигналинга охарактеризованы, однако их роль в химическом взаимодействии партнеров в большинстве случаев требует дальнейшего изучения. Показано, что явление QS и его участники причастны к регуляции взаимодействий между про- и эукариотами, в том числе к формированию биопленок, синтезу фитогормонов, трансферу плазмид, продукции факторов вирулентности, биолюминесценции, споруляции, образованию клубеньков (Л.М. Бабенко с соавт., 2017). Различия в строении молекул обеспечивают распознавание бактериями собственных АГЛ и отделение чужеродных. Перенос АГЛ от бактерии к растению-хозяину осуществляется при помощи мембранных везикул (М. Toyofuku, 2019). В последние годы активно изучаются генетика, геномика, биохимия и сигнальное разнообразие молекул QS. Регулирование функций ризосферы наиболее динамичного сайта взаимодействия растения и ассоциированной с ним микрофлоры с участием АГЛ приобретает особое значение при разработке новых биотехнологических подходов, направленных на повышение урожайности и стрессоустойчивости аграрных культур. Одна из эффективных технологий повышения устойчивости к биотическим и абиотическим стрессам - предпосевная обработка (праймирование) семян (А. Shrestha с соавт., 2020). Установлены прямые (направленные на растения) и косвенные (через ризосферную микрофлору) эффекты АГЛ-праймирования (O.V. Moshynets с соавт., 2019). Праймирование АГЛ индуцирует усиление роста растений, повышение содержания фотосинтетических пигментов, вызывает изменения в балансе эндогенных фитогормонов в органах и тканях, влияет на формирование механизмов защиты (A. Schikora c соавт., 2016; А. Shrestha с соавт., 2020). АГЛ, отвечающие требованиям интенсивного органического земледелия, позиционируются как перспективные экологические фитостимуляторы и фитомодуляторы, способные повысить количество и качество сельскохозяйственной продукции.

Ключевые слова: ацилгомосеринлактоны, quorum sensing (QS), quorum quenching (QQ), растительно-микробный сигналинг, АГЛ-праймирование, АГЛ-мимикрия, фитостимуляторы, фитомодуляторы, стрессоустойчивость.

* Работа выполнена при финансовой поддержке Национальной академии наук Украины в рамках проекта № 0120U102936 «Разработка инновационной биотехнологии повышения устойчивости и урожайности злаков на основе комплекса сигнальных молекул растительного и бактериального происхождения для защиты окружающей среды и ее восстановления» (2020-2024). 
В последние десятилетия изучение механизмов формирования устойчивости растений к неблагоприятным факторам окружающей среды вошло в число наиболее актуальных задач молекулярной физиологии растений в связи с глобальными климатическими изменениями и антропогенной нагрузкой на биосферу. Экстремальные температуры - один из самых распространенных абиотических стрессоров. Глобальное потепление угрожает не только сельскому хозяйству, но и сохранению биоразнообразия. Прогнозируемое повышение средней температуры на $1{ }^{\circ} \mathrm{C}$ может привести к сокращению видового разнообразия растений на треть (1). В то же время не следует оставлять без внимания вопросы холодо- и морозоустойчивости растений. Зимние оттепели, чередующиеся с морозами, вызывают серьезные повреждения растений, снижают урожайность. Более раннее наступление метеорологической весны повышает вероятность их повреждения в результате весенних заморозков. Еще один неблагоприятный климатический фактор, действие которого усиливается, - это недостаток влаги и перераспределение суммы годовых осадков (2). Повышение температуры и изменения в характере осадков приводят к нарушению гидрологического режима и сокращению водных ресурсов. Так, на территории Украины в последнюю четверть XX века наблюдалась устойчивая тенденция к снижению годового количества осадков (3). При этом возросла частота осадков ливневого характера, что также негативно сказывается на продуктивности растений. Серьезную угрозу создают кислотные дожди и загрязнение окружающей среды тяжелыми металлами. Экологическое равновесие нарушается из-за нерационального использования химических средств защиты растений. Около 2 млн т пестицидов ежегодно используется в мировом аграрном производстве. На 2020 год прогнозировалось увеличение глобального применения пестицидов до 3,5 млн т (4), однако проблему эффективного повышения урожайности аграрных культур это не решило.

Для обеспечения растущих потребностей в продуктах питания необходимы безопасные агробиотехнологии, которые позволят повысить количество и качество сельскохозяйственной продукции (5-8). Как перспективный биотехнологический подход рассматривается использование бактериальных инокулятов, улучшающих рост растений, а также бактериальных регуляторов роста для предпосевного праймирования семян и фолиарной обработки растений $(5,9,10)$. Такая «зеленая» технология становится все более популярной. В некоторых случаях природные фитостимуляторы способны улучшить стрессоустойчивость посевов и повысить урожайность без нежелательных воздействий на окружающую среду (11).

В последние годы внимание сосредоточено на феномене, получившем название «quorum sensing» (QS). Это система межклеточной коммуникации бактерий, которая зависит от плотности клеточной популяции и координирует формирование ответов на изменение условий среды $(12,13)$. QS-системы образуют сигнальные молекулы аутоиндукторов, легко диффундирующие из клеток в окружающую среду и обратно $(14,15)$. QS-регуляция установлена для более чем 500 видов бактерий. Системам QS принадлежит ключевая роль в регуляции метаболических и физиологических процессов в бактериальной клетке $(16,17)$. Бактериальный сигналинг воспринимается эукариотическими организмами, образующими симбиоз с микробными сообществами, и обеспечивает взаимодействие между бактериями и растениями $(7,18-21)$. Рост и развитие растения, ассимиляция питательных веществ, стрессоустойчивость во многом определяются характером такого взаимодействия (22-24). В QS-регуляции грамотрицательных 
бактерий задействованы сигнальные соединения класса ацилгомосеринлактонов (АГЛ) (25), которые проявили себя как эффективные стимуляторы роста растений и фитомодуляторы устойчивости к биотическим и абиотическим стрессорам $(8,26)$.

Целью нашего обзора стал анализ и обобщение новейших литературных данных о роли бактериального «quorum sensing» и ацилгомосеринлактонов в формировании и функционировании растительно-микробного сигналинга, участии АГЛ в регуляции роста и развития растений, формировании устойчивости, а также перспективах использования этих соединений для создания экологически безопасных препаратов, способных повышать урожайность аграрных культур.

Влияние микроорганизмов PGPR-группы на рост, развитие и устойчивость растений. Рост и развитие растений зависят от условий окружающей среды, прежде всего почвы, в которой сконцентрированы различные формы живых организмов. Эдафическая микробиота существенно влияет на минеральное питание и почвообразующие процессы в целом. В свою очередь корневая система активно участвует в формировании среды обитания растений. Основной экологической нишей, которую занимают ризосферные бактерии, служит зона активного выделения корневых экзометаболитов. Корневая система - своеобразная форма коммуникации растения и почвенной микрофлоры, основной источник физиологически активных веществ, которые в течение вегетации выполняют роль связующего звена в донорно-акцепторном взаимодействии между растениями и микробными сообществами в почве $(22,27,28)$. Микробиота ризосферы влияет на иммунитет растения и супрессивность почвы (29). Благодаря высокой секреторной активности корней, микроорганизмы почвы обеспечиваются питательным субстратом и образуют прочные ассоциативные связи как в ризоплане, так и в ризосфере. Вместе с тем корневые экзометаболиты могут быть одним из факторов, определяющих фунгистазис почвы. От их состава и концентрации зависит реакция патогенов - стимуляция или подавление развития (30). Каждое растение имеет систему защиты от патогенов, однако способ, позволяющий обнаружить и отличить полезные микроорганизмы от патогенов, до конца не изучен. Полагают, что у растения имеются рецепторы, которые реагируют на микробные молекулы (31). В этом процессе участвуют как различные механизмы передачи сигналов (хемоатракция, образование клубеньков), так и непосредственно химические вещества (органические кислоты, сахара, флавоноиды, летучие органические вещества) (32). Наличие определенного соединения становится сигналом для начала колонизации корня или процесса формирования клубеньков. После колонизации корня бактерии корректируют метаболизм растения (33).

Бактерии, колонизирующие поверхность корней и ризосферу и имеющие полезные для растений свойства, определяют как PGPR-группу (plant growth promoting rhizobacteria) (22). Представители PGPR-группы способны преодолевать эндодермальный барьер. Они попадают в растение преимущественно через кортекс корня, инфицируют сосудистую систему и образуют эндофитные популяции в корнях, стеблях, листьях и других органах (22). Влияние PGPR на рост и развитие растений носит прямой и опосредованный характер. Так, при прямом воздействии PGPR происходит активный синтез фитогормонов, стимулирующих рост (ауксинов, цитокининов и гиббереллинов), а также торможение синтеза стрессовых фитогормонов (этилена, салициловой и абсцизовой кислот), усиливается поглощение 
питательных веществ и воды (с помощью фиксаторов $\mathrm{N}_{2}$, солюбилизаторов фосфатов, продуцентов сидерофоров). Косвенное воздействие PGPR заключаются в индукции защитных механизмов, а именно активации процессов синтеза антибиотиков и литических ферментов клеточных стенок (хитиназ), которые проявляют фитостимулирующий и биопестицидний эффекты (34). Благодаря таким свойствам PGPR используются как компоненты микробиологических удобрений для повышения урожайности аграрных культур экологически безопасным способом (5).

Согласно данным литературы, фитостимулирующим эффектом обладают PGPR родов Rhizobium, Klebsiella, Clostridium, Nostoc, Anabaena, Bacillus. Они положительно влияют на процессы солюбилизации фосфора и азотфиксацию, стимулируют синтез фитогормонов, индуцируют механизмы защиты от патогенов и ускоряют восстановление после воздействия стресса $(5,35)$. Индуцируя процессы солюбилизации и хелатирования, а также окислительно-восстановительные реакции, PGPR облегчают доступность почвенных микронутриентов, а благодаря биофортификации азота, железа, цинка и селена обеспечивают необходимое содержание этих микроэлементов в растениях. PGPR смягчают негативные последствия действия высоких температур, засухи, засоления и других абиотических стрессоров, что позволяет использовать их при создании устойчивых микробиологических препаратов (36).

Одна из важнейших задач биотехнологии - фиторемедиация загрязненных почв, возрождение малопригодных для земледелия территорий. PGPR как стимуляторы роста и модуляторы устойчивости растений позиционируются в качестве перспективных детоксикантов $(37,38)$.

Экологически безопасной альтернативой химическим удобрениям и агрохимикатам, которые пагубно влияют на окружающую среду, служат микробиологические удобрения (5). В настоящее время на рынке представлены четыре группы микробиологических препаратов, повышающих плодородие почвы и обеспечивающих защиту растений. Это азотфиксаторы (ассоциативные и симбиотические), бактерии-фосфатмобилизаторы, фитостимуляторы, а также бактериальные препараты, которые разлагают остатки растений (39). Однако низкое качество микробиоудобрений вызывает недоверие аграриев и усложняет коммерциализацию. Для увеличения производства и широкого их внедрения необходимо стабилизировать конечный продукт.

Межклеточная коммуникация микроорганизмов. Формирование биопленки - древний и неотъемлемый компонент жизненного цикла прокариот, а также ключевой фактор, обеспечивающий выживание в различных экологических нишах $(20,40,41)$. Биопленка - высокоорганизованное бактериальное образование, своеобразная экологическая ниша со стабильными условиями существования, в которой формируются сложные трофические связи $(14,17)$. В биопленках бактерии координируют и синхронизируют работу индивидуальных геномов, что позволяет популяции функционировать подобно многоклеточному организму (42). Взаимодействие отдельных клеток в бактериальной популяции необходимо для ее выживания в изменяющихся экологических условиях и установления симбиотических или паразитарных взаимоотношений с многоклеточными организмами $(17,43)$. Координированная деятельность бактериальных клеток в биопленке осуществляется благодаря QS взаимодействию специализированных химических молекул - коммуникативных медиаторов, или аутоиндукторов (АИ), названных так из-за способности стимулировать 
собственный биосинтез $(12,44)$.

Сигнальные молекулы-аутоиндукторы фактически служат регуляторами генной экспрессии. Они свободно диффундируют через клеточные мембраны, создавая условия, при которых бактериальная клетка приобретает способность реагировать на любые изменения их внутриклеточной концентрации и таким образом определять размеры популяции (45). Межклеточный QS-сигналинг координирует поведение бактериальной популяции. С ростом численности бактерий содержание АИ возрастает, а после достижения пороговой концентрации АИ связывают и активируют рецепторные белки (42). Лиганд-рецепторный комплекс инициирует транскрипцию QS-регулируемых генов и определяет фенотип популяции, который зависит от плотности бактериальных клеток.

Бактериальные QS-системы (с некоторым приближением) можно считать прототипом сложных регуляторных систем высших организмов (гормональной и иммунной), которые используют медиаторы для координации функций различных клеток и формирования адаптационной реакции на уровне тканей, органов и организма в целом (46). Среди медиаторов бактериального QS наиболее исследованы лактоны - низкомолекулярные химические соединения класса ацильных производных лактона L-гомосерина. Сигнальные системы, в состав которых входят N-ацилгомосеринлактоны (АГЛ) и их рецепторы, наиболее распространены у большинства грамотрицательных бактерий $(25,47)$. АГЛ содержат пятичленное гомосеринлактоновое кольцо и присоединенную к нему амидной связью вариабельную ацильную боковую цепь (рис. 1). Гомосеринлактоны были открыты K.H. Nealson c coaвт. (48) при изучении биолюминесцентной бактериисимбионта Vibrio fischeri, живущей в фотофорах гавайских кальмаров и в концентрации $10^{11}$ клеток вызывающей свечение этих органов.

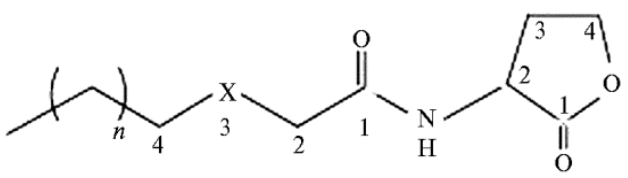

Рис. 1. Структура молекулы ацилгомосеринлактона: X - возможные заместители радикалов в третьем атоме углерода боковой цепи $(\mathrm{H}, \mathrm{OH}$, O), $n$ - число атомов углерода ацильной боковой цепи.

Молекулы АГЛ, синтезированные бактериями разных видов, различаются по длине цепи и наличию или отсутствию радикалов в боковой цепи у третьего углеродного атома. Различия в строении молекул обеспечивают распознавание бактериями собственных и чужеродных АГЛ (17). Бактерии синтезируют как короткоцепочечные АГЛ (3-6 атомов углерода в ацильной группе), которые свободно диффундируют сквозь клеточную мембрану, так и длинноцепочечные АГЛ (1016 углеродных атомов), способные встраиваться в клеточную мембрану (7). Кроме участия в функционировании системы QS, АГЛ могут непосредственно влиять на клетки эукариотических организмов, в частности растений (49). Биосинтез АГЛ осуществляется ферментами АГЛ-синтазами LuxIтипа. По мере того, как популяция бактерий возрастает, АГЛ накапливаются до определенного порогового значения и связываются с соответствующими рецепторными белками, образуя комплексы, регулирующие экспрессию определенных бактериальных генов (50) (рис. 2). Недавние исследования показали, что бактериальные сигнальные молекулы переносятся мембранными везикулами. Ранее считалось, что везикулы образуются в результате блеббинга клеточной мембраны, однако впоследствии было установлено, что они возникают также после взрывного лизиса или гибели клеток, что расширяет наши представления о межклеточном взаимодействии 


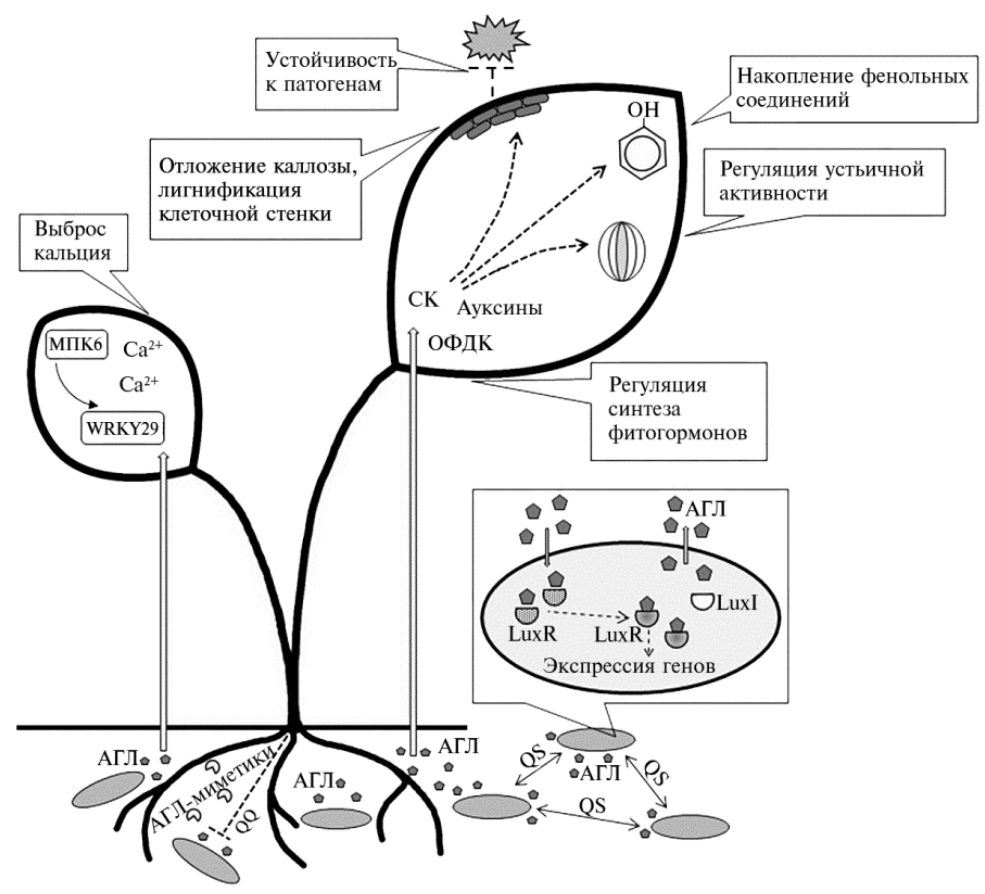

Рис. 2. Физиолого-биохимические процессы, индуцируемые ацилгомосеринлактонами (АГЛ). В системе «quorum sensing» (QS) бактериальные клетки продуцируют молекулы АГЛ, в синтезе которых участвуют АГЛ-синтазы двух типов - LuxI и LuxR. Белок LuxI задействован непосредственно в синтезе АГЛ. LuxR выполняет функцию связывающего белка-промотора. C увеличением плотности бактериальной популяции возрастает концентрация АГЛ. После достижения порогового уровня АГЛ проникают в клетку, связываются с белками типа LuxR, активируют экспрессию генов-мишеней. Молекулы АГЛ, проникая в клетки корня, вызывают различные ответные реакции растений, среди которых: запуск сигнального каскада с участием митоген-активированной протеинкиназы (МПК), экспрессия факторов транскрипции WRKYтипа, увеличение концентрации ионов $\mathrm{Ca}^{2+}$ в цитозоле, активация каскада оксофитодиеновой кислоты (ОФДК), синтез фитогормонов - салициловой кислоты (СК), ауксинов. Формируются защитные реакции, среди которых отложение каллозы, накопление фенольных соединений, регуляция устьичной проводимости. Система «quorum quenching» (QQ) вмешательства растения позволяет манипулировать QS-сигналингом, избирательно угнетая синтез АГЛ, конкурируя с АГЛ за связывание с рецепторными белками, угнетая активность QS-контролируемых генов. АГЛ-миметики - растительные метаболиты, продуцируемы корневыми клетками и регулирующие бактериальный QS, рассматриваются как один из компонентов QQ. Приведенные сведения адаптированы из А. Schikora с соавт., 2016 (19).

QS регулирует разнообразные физиологические процессы у грамотрицательных бактерий. Многие патогены растений и животных используют QS для управления вирулентностью, что весьма перспективно для практических целей (52). В последнее время появились биотехнологические разработки, направленные на получение антагонистов АГЛ (53). Такие вещества применяют для защиты сельскохозяйственных культур от фитопатогенов, а в медицине и ветеринарии используют как антимикробные препараты. С помощью QS регулируется синтез антибиотиков, что позволяет активировать рост бактериальных культур в производственных условиях. Однако использование QS и АГЛ как специфических регуляторов процессов, осуществляемых бактериями, ограничивается недостаточной изученностью механизма их действия и эффектов их аутоиндукторов. В отдельных работах сообщается, что изучение межклеточных коммуникаций in vitro не дает полного представления о механизмах функционирования и эффектах QS-систем и АГЛ и что для дальнейшего исследования этого феномена необходимы 
новые подходы в системе in situ (54).

Роль растения-хозяина в регуляции бактериально го Q S. Поскольку бактерии и эукариотические организмы совместно эволюционировали в течение миллионов лет, у эукариот сформировались механизмы, позволяющие воспринимать QS-сигналинг, манипулировать бактериальным взаимодействием и реагировать на него (55). Молекулярные механизмы этих процессов до конца не выяснены (13). В противоположность системе QS, которая регулирует поведение бактериальных клеток при взаимодействии с хозяином, у растений функционирует система вмешательства «quorum quenching»(QQ), позволяющая манипулировать бактериальным сигналингом (56). Молекулярные механизмы QQ растительных метаболитов заключаются в подавлении синтеза АГЛ, конкуренции с АГЛ за связывание с рецепторными белками, снижении экспрессии QS-контролируемых генов (57-60). Особый интерес представляют растительные метаболиты, которые взаимодействуют с рецепторами АГЛ и могут активировать транскрипцию целевых бактериальных генов (см. рис. 2). Способность таких соединений замещать АГЛ при взаимодействии с рецепторными белками получила название АГЛ-мимикрии (61).

АГЛ-мимикрия - это один из механизмов воздействия на QS бактерий. Корневые экссудаты растений содержат низкомолекулярные сигнальные соединения, так называемые АГЛ-миметики, регулирующие бактериальный QS и действующие как антагонисты или синергисты $(63,63)$. Предполагается, что АГЛ-миметики способны регулировать функции и состав бактериальной популяции ризосферы, формируя ризомикробиом растений (64). В корневом экссудате Medicago truncatula обнаружено до 20 сигнально-мимических соединений, способных влиять на бактериальный QS. Интенсивность секреции и состав таких соединений изменялись с возрастом растения, а также после обработки проростков растворами АГЛ (62). Интересно отметить, что синтез АГЛ-миметиков активируется у растений под воздействием QS сигналов ризобактерий. Химическое строение растительных молекул, влияющих на АГЛ-опосредованный бактериальный QS, до конца не выяснено. Казалось бы логичным, чтобы АГЛ-миметики имели структуру, близкую к АГЛ, однако проведенные исследования указывают на различия в строении этих соединений $(65,66)$.

Первым идентифицированным эукариотическим АГЛ-миметиком, структурно отличающимся от АГЛ, но способным активировать бактериальную QS-систему, стал люминохром (67). Он, вероятно, непосредственно взаимодействуют с АГЛ-связывающим карманом рецепторного белка LasRy Pseudomanas aeruginosa (АГЛ-рецептор LuxR-тиna) (68). L-канаванин, аналог аргинина, обнаруженный в экссудатах семян люцерны, подавлял QS-регуляцию у Sinorhizobium meliloti (69). Розмариновая кислота стимулировала активность регулятора транскрипции RhlR у Pseudomonas aeruginosa (66). Кумаровая кислота, секретируемая корнями растений, формирует особый QSсигнал - кумароил-гомосеринлактон, воспринимаемый некоторыми бактериями (44). Флавоноиды катехин и нарингенин многих растений проявляли активность QS-миметиков (70, 71). АГЛ-миметики корневых экссудатов риса и бобов регулировали образование бактериальных биопленок, что указывает на роль этих соединений в формировании растительно-бактериального симбиоза (65). Arachis hypogaea формирует ризобиальный симбиоз с Bradyrhizobium spp., синтезирующим длинноцепочечные АГЛ. Семенной и корневой экссудаты $A$. hypogaea, содержащие QS-миметики, подобные длинноцепочечным АГЛ, стимулировали рост бактерий с длинноцепочечным АЛГ опосредованным QS-сигналингом и подавляли рост и развитие 
бактерий с короткоцепочечным QS АГЛ-сигналингом (72).

Другой механизм воздействия на бактериальный QS основан на доступности и стабильности молекул АГЛ в зоне ризосферы. Так, при совместном культивировании Sinorhizobium meliloti и Arabidopsis thaliana количество АГЛ, синтезированных бактериями, уменьшалось, что могло быть обусловлено как угнетением синтеза этих соединений растением-хозяином, так и изменениями их количества и доступности (73). Концентрация АГЛ в ризосфере зависит от адсорбции на частицах почвы, гидролиза лактонного кольца, температуры и рН окружающей среды. Еще одним фактором деградации молекул АГЛ в ризосфере становится их гидролиз растительными QQ ферментами. Некоторые растения способны синтезировать ферменты, разрушающие бактериальные АГЛ $(74,75)$. Деградация АГЛ растительными ферментами - процесс видоспецифичный. Так, разрушение АГЛ в ризосфере двудольных растений протекало быстро, тогда как в ризосфере однодольных - медленно либо вовсе отсутствовало $(74,76)$. Механизм разрушения АГЛ в ризосфере растений недостаточно изучен. Предполагают, что по аналогии с бактериальной деградацией в нем могут участвовать два фермента - АГЛ-лактоназы, гидролизующие лактонное кольцо, либо АГЛацилазы, гидролизирующие амидную связь между ацильной боковой цепью и гомосеринлактоном, в результате чего от гомосеринлактона отделяется жирная кислота. Однако существование такого механизма у растений на сегодняшний день не установлено $(74,76)$. Предполагается, что в процессе коэволюции растения выработали конкретные механизмы обнаружения АГЛ во внеклеточной среде и стратегии манипулирования QS-системами бактерий. Таким образом, благодаря системе вмешательства «quorum quenching» растение-хозяин может влиять на АГЛ-опосредованный бактериальный сигналинг и определять характер взаимоотношений между партнерами в зоне ризосферы.

Молекулярные механизмы действия ацилгомосе р и н л а к т о н о в. Праймирование АГЛ включает сигнальные механизмы защитной реакции у растений, в результате чего происходит модуляция салицилат-зависимого и оксилипин-индуцируемого стрессовых ответов, МАПкиназного каскада, замыкание устьиц, утолщение клеточной стенки, синтез фенольных метаболитов $(18,20,77)$. Бактерии PGPR-группы индуцируют секрецию поверхностно-активных метаболитов и синтез летучих соединений, которые активируют защитные сигнальные пути и помогают растениям противостоять атаке патогенов (78). Так, обработка корней томатов АГЛ, продуцируемых ризобактерией Serratia liquefaciens MG1, индуцировала резистентность к Alternaria alternata. В формировании устойчивости к действию патогена был задействован активированный салициловой кислотой (CK) сигнальный путь. Обработка корней томатов бутаноилгомосеринлактоном (С4-АГЛ) и гексаноилгомосеринлактоном (С6-АГЛ) вызывала экспрессию гена патоген-ассоциированного протеина 1a (PR1a) и генов двух хитиназ - компонентов CK/этилен-зависимого пути в листьях томата. Полученные результаты показали, что короткоцепочечные АГЛ в растениях томата выступают триггером СК-зависимого сигнального пути (77). После обработки корней арабидопсиса тетрадеканоилгомосеринлактоном (С14-АГЛ) под действием патоген-ассоциированного молекулярного паттерна (pathogen-associated molecular pattern, PAMP) усиливалась активность AtMPK3 и AtMPK6, которые экспрессировали транскрипционные факторы WRKY22 и WRKR29, причастные к синтезу PR1 $(18,79)$. Именно в ответ на действие патогена растения активно синтезируют патоген-зависимый 
протеин PR1 $(80,81)$. АГЛ стимулировали синтез оксофитодиеновой (ОФДК) и салициловой кислот, задействованных в формировании защитной реакции. Растения арабидопсиса, обработанные С14-АГЛ, накапливали СК и ОФДК в листьях, что усиливало экспрессию генов HSP70, HSP17 и CYP81D11, которые отвечают за синтез белков теплового шока и цитохрома P450 (49).

Абсцизовая кислота (АБК) и СК индуцируют закрывание устьиц, выполняя ключевую роль в адаптации к стрессам (82). При праймировании пораженных Pseudomonas syringae растений арабидопсиса $\mathrm{C}_{14}$-АГЛ активировалось закрывание устьиц, однако праймирование не повлияло на активность генов $R D 22, R D 29$ и $R A B 18$, причастных к синтезу АБК $(49,83)$. Механизм движения замыкающих клеток устьиц в условиях стресса связывают с аккумуляцией АБК и активацией специфических ионных каналов (84). $\mathrm{Ca}^{2+}$-независимая протеинкиназа Open Stomata 1 (OST1) и $\mathrm{Ca}^{2+}$-зависимая протеинкиназа (CPKs) - ключевые ферменты для АБК-индуцированной активации анионного канала медленного типа SLAC1 и закрывания устьиц $(82,85,86)$. Предполагают, что СК-сигналинг интегрируется с АБК-сигналингом (82). Блокировка СК-индуцированного закрывания устьичного аппарата и СК-активация анионного канала медленного типа обнаружена у мутантов арабидопсиса $c p k 3$ и cpk6 с нарушениями в синтезе CPKs и не выявлена у мутанта ost 1-3 с нарушениями в синтезе $\mathrm{OST}_{1}$ (87). Ключевыми для CK-сигналинга служат сайты фосфорилирования SLAC1 AБК-сигналинга - серин-59 и серин-120 (88). Хемилюминесцентная идентификация супероксиданиона показала, что СК-сигналинг не требует активации $c p k 3$ и $c p k 6$ для образования активных форм кислорода (АФК). СК активирует опосредованный пероксидазой сигнал АФК, индуцированный в $\mathrm{Ca}^{2+} / \mathrm{CPK}-$ зависимой ветви АБК-сигналинга, а не OST1-зависимую сигнальную ветвь в замыкающих клетках устьиц (82). После обработки АГЛ увеличивалась устьичная проводимость и листовая транспирация, что усиливало поступление нутриентов к бактериям-колонизаторам корней фасоли (89).

У генетически модифицированных растений табака, содержащих бактериальные гены синтеза и деградации АГЛ, эффективная защита от патогенов формировалась у АГЛ-синтезирующих растений, тогда как растения, содержащие АГЛ-деградирующие гены, не могли обеспечить защиту от поражения патогенами. Экзогенная обработка С14-АГЛ усиливала системную резистентность арабидопсиса к патогенам Golovinomyces orontii и P. syringae и ячменя - к Blumeria graminis f. sp. hordei (18). После обработки раствором С14-АГЛ зафиксировано отложение каллозы, накопление фенольных соединений, лигнификация клеточных стенок, изменение в содержании оксилипинов и закрытие устьиц растений $(7,49)$. Удлинение первичного корня у дикого генотипа Arabidopsis thaliana, индуцированное обработкой растворами С6-АГЛ и октаноилгомосеринлактона (С8-АГЛ), не наблюдалось у мутантов, нечувствительных к АГЛ (90). Обработка растений

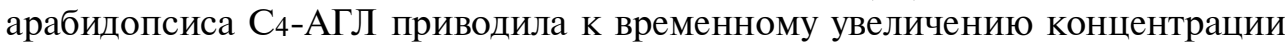
$\mathrm{Ca}^{2+}$ в цитозоле, а обработка $\mathrm{C}_{6}$-АГЛ индуцировала увеличение концентрации кальций-связывающего протеина (кальмодулина). Эти результаты свидетельствуют о причастности ионов кальция к восприятию бактериального АГЛ-сигналинга $(32,91)$. Предполагают, что в восприятии АГЛ сигналов задействованы Cand2 и Cand7 G-протеины (G-protein coupled receptors, GPCRs), которые известны как триггеры процессов клеточной пролиферации, формирования защитных реакций, световосприятия, устьичной проводимости, регуляции ионных каналов, прорастания семян, 
синтеза гиббереллинов, брассиностероидов, абсцизовой и жасмоновой кислот, ауксинов и этилена (см. рис. 2). Основанием для такого предположения послужили результаты ПЦР-анализа растений, праймированных С6-АГЛ и

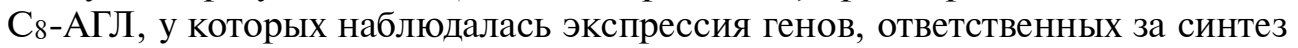
Cand2 и Cand7 (92).

Фитостимулирующий и фитопротекторний эффекты праймирования и фолиарной обработки растворами АГЛ. Климатические условия в значительной степени влияют на качество урожая, а неблагоприятные изменения температуры и водного режима снижают устойчивость растений к бактериальным и грибным инвазиям. Одна из эффективных технологий повышения устойчивости к биотическим и абиотическим стрессорам - предпосевное праймирование семян, которое улучшает прорастание и активирует защитные механизмы (6-8). Рост и развитие растений стимулируют также бактериальные инокулянты. Они улучшают минеральное питание и уменьшают влияние патогенов благодаря конкуренции и стимуляции защитных систем $(19,78)$. Так, бактерия Serratia marcescens индуцирует системную устойчивость растений Solanum lycopersicum к грибному возбудителю Alternaria alternata (93), а обработка корней растворами синтетических АГЛ усиливает экспрессию генов, задействованных в формировании механизмов защиты листьев томата (77). После предпосевного праймирования С6-АГЛ в 1,2 раза увеличилось число проросших зерен и в 1,4 раза - размеры колеоптиля и корня озимой пшеницы (8). Полевые исследования показали увеличение биомассы растений на стадии кущения в 1,4 раза, урожайности - в 1,5 раза, качества зерна - в 1,3 раза. У поколения $\mathrm{F}_{1}$, выращенного из семян от праймированных родительских растений, также зафиксировано увеличение урожайности, что свидетельствует о сохранении эффекта праймирования (8).

На рост и устойчивость растений к болезнетворным микроорганизмам положительно влияют ризосферные и филосферные ассоциированные микробные сообщества $(94,95)$. АГЛ, попавшие в почву с праймированными семенами, стимулируют рост PGPR бактерий родов Bacillus и Pseudomonas, колонизирующих поверхность корня и угнетающих активность патогенов (96). Под действием АГЛ в зоне ризосферы увеличивается количество амилолитических бактерий, которые участвуют в деградации отмерших корневых клеток, усиливается рост корней, возрастает поступление необходимых другим ризосферным бактериям сахаров. АГЛ влияют на формирование защитной реакции растений, инициируют системную устойчивость и улучшают распознавание патогенных микроорганизмов (97). Праймирование семян Cicer arietinum $\mathrm{C}_{4}$-АГЛ усиливало рост и повышало стрессоустойчивость растений (26). Праймированные семена хорошо прорастали в условиях моделируемого окислительного (5 мМ H2 $\left.\mathrm{O}_{2}\right)$ и солевого (200 мМ $\mathrm{NaCl}$ ) стрессов. У проростков увеличивалась биомасса, повышалось содержание хлорофилла и протеинов, а также возрастала устойчивость к поражению Fusarium oxysporum f. sp. ciceri (26). С6-АГЛ способны стимулировать процессы роста и корнеобразования $(90,98,99)$, а также индуцировать системную устойчивость к широкому спектру патогенов у многих видов растений (100). Таким образом, различные исследования продемонстрировали, что бактериальные АГЛ могут быть использованы для улучшения роста и повышения урожайности растений, снижения зависимости от фунгицидов и удобрений, для борьбы с патогенами и стрессорами (101).

Итак, в дистанционной трансдукции сигналов в системе фитосферный бактериальный биоценоз-растение участвуют молекулы-медиаторы 
бактериального происхождения - ацилгомосеринлактоны. Среди молекул АГЛ, синтезированных бактериями разных видов, выделяют короткоцепочечные с 3-6 атомами углерода в ацильной группе и длинноцепочечные с 10-18 углеродными атомами. Различия в строении молекул обеспечивают распознавание бактериями собственных АГЛ и отделение чужеродных. Молекулам АГЛ принадлежит ключевая роль в кооперативной деятельности бактериальных популяций, колонизации ими новых экологических ниш и регуляции взаимодействия между партнерами в ризосфере. АГЛ, синтезированные ассоциированными с растениями бактериями, влияют на состав микробных сообществ и процессы жизнедеятельности растений. Растения принимают бактериальные АГЛ-сигналы и реагируют на них, адаптируясь к изменяющимся условиям и выделяя собственные АГЛ-миметики. Перенос АГЛ от бактерии к растению-хозяину осуществляется при помощи мембранных везикул. Большинство фитопатогенных бактерий используют системы «quorum sensing» (QS), непосредственно связанные с вирулентностью. Экспрессия факторов вирулентности, регулируемых QS, становится одной из причин возникновения инфекции. Сигнальные молекулы и системы QS фитопатогенных бактерий исследованы достаточно подробно. Изучение генной экспрессии регулируемых QS функций вирулентности привело к разработке стратегии вмешательства в QS для борьбы с бактериальными болезнями растений. Известный пример - системы «quorum quenching» бактерий рода Bacillus, которые синтезируют лактоназу и ацилазу, расщепляющие $\mathrm{N}$-ацилгомосеринлактоны. Для вмешательства в системы QS конкурентных видов бактерии используют летучие органические соединения. Растения, в свою очередь, синтезируют соединения, подобные АГЛ (химическая мимикрия), которые могут подавлять или стимулировать системы QS бактерий. В последние годы активно изучается генетика, геномика, биохимия и сигнальное разнообразие молекул QS. Регулирование функций ризосферы, наиболее динамичного сайта взаимодействия растения и ассоциированной с ним микрофлоры с участием АГЛ, приобретает особое значение при разработке новых биотехнологических подходов, направленных на повышение урожайности и стрессоустойчивости аграрных культур. АГЛ индуцируют усиление роста, повышение содержания фотосинтетических пигментов, вызывают изменения в соотношении фитогормонов в органах и тканях, влияют на формирование механизмов защиты, что повышает урожайность сельскохозяйственных культур. Поскольку АГЛ соответствуют требованиям интенсивного органического земледелия, их рассматривают как перспективные экологические фитостимуляторы и фитомодуляторы.

\section{ЛИТЕРАТУРА}

1. Thuiller W., Lavorel S., Araújo M., Sykes M., Prentice I.C. Climate change threats to plant diversity in Europe. Proceedings of the National Academy of Sciences, 2005, 102(23): 8245-8250 (doi: 10.1073/pnas.0409902102).

2. Hsu J.S., Powell J., Adler P.B. Sensitivity of mean annual primary production to precipitation. Global Change Biology, 2012, 18(7): 2246-2255 (doi: 10.1111/j.1365-2486.2012.02687.x).

3. Моргун В.В., Кірізій Д.А. Перспективи та сучасні стратегії поліпшення фізіологічних ознак пшениці для підвищення іiі продуктивності. Физиология и биохимия культурных растений, 2012, 44(6): 463-483.

4. Sharma A., Kumar V., Shahzad B., Tanveer M., Sidhu G.P.S., Handa N., Kohli S.K., Yadav P., Bali A.S., Parihar R.D., Dar O.I., Singh K., Jasrotia S., Bakshi P., Ramakrishnan M., Kumar S., Bhardwaj R., Thukral A.K. Worldwide pesticide usage and its impacts on ecosystem. SN Applied Sciences, 2019, 1: 1446 (doi: 10.1007/s42452-019-1485-1).

5. Stamenković S., Beškoski V., Karabegović I., Lazić M., Nikolić N. Microbial fertilizers: a 
comprehensive review of current findings and future perspectives. Spanish Journal of Agricultural Research, 2018, 16(1): e09R01 (doi: 10.5424/sjar/2018161-12117).

6. Floryszak-Wieczorek J., Arasimowicz-Jelonek M., Abramowski D. BABA-primed defense responses to Phytophthora infestans in the next vegetative progeny of potato. Frontiers in Plant Science, 2015, 6: 844 (doi: 10.3389/fpls.2015.00844).

7. Schenk S.T., Schikora A. AHL-priming function via oxylipin and salicylic acid. Frontiers in Plant Science, 2015, 5: 784 (doi: 10.3389/fpls.2014.00784).

8. Moshynets O.V., Babenko L.M., Rogalsky S.P., Iungin O.S., Foster J., Kosakivska I.V., Potters G., Spiers A.J. Priming winter wheat seeds with the bacterial quorum sensing signal N-hexanoyl-L-homoserine lactone (C6-HSL) shows potential to improve plant growth and seed yield. PLoS ONE, 2019, 14(2): e0209460 (doi: 10.1371/journal.pone.0209460).

9. Paradiković N., Vinković T., Vrček I.V., Tkalec M. Natural biostimulants reduce the incidence of BER in sweet yellow pepper plants (Capsicum annuum L.). Agricultural and Food Science, 2013, 22(2): 307-317 (doi: 10.23986/afsci.7354).

10. Maksimov I.V., Yarullina L.G., Surina O.B. The effect of exogenous phytohormones on resistance of wheat calluses to Tilletia caries (D.C.) Tul. \& C. Tul. American Journal of Plant Sciences, 2014, 5(12): 1745-1754 (doi: 10.4236/ajps.2014.512189).

11. Tsygankova V., Shysha E., Andrusevich Y., Galkin A., Iutynska G., Yemets A., Blume Y. Using of new microbial biostimulants for obtaining in vitro new lines of Triticum aestivum L. cells resistant to nematode H. avenae. European Journal of Biotechnology and Bioscience, 2016, 4(4): 41-53.

12. Abisado R.G., Benomar S., Klaus J.R., Dandekar A.A., Chandler J.R. Bacterial quorum sensing and microbial community interactions. mBio, 2018, 9(3): e02331-17 (doi: 10.1128/mBio.02331-17).

13. Chagas F.O., Pessotti R.C., Caraballo-Rodríguez A.M., Pupo M.T. Chemical signaling involved in plant-microbe interactions. Chemical Society Reviews, 2018, 47(5): 1652-1704 (doi: 10.1039/C7CS00343A).

14. Bassler B. Small talk. Cell-to-cell communication in bacteria. Cell, 2002, 109(4): $421-424$ (doi: 10.1016/S0092-8674(02)00749-3).

15. Miller M.B., Bassler B.L. Quorum sensing in bacteria. Annual Review of Microbiology, 2001, 55: 165-199 (doi: 10.1146/annurev.micro.55.1.165).

16. Frederix M., Downie A.J. Quorum sensing: regulating the regulators. Advances in Microbial Physiology, 2011, 58: 23-80 (doi: 10.1016/B978-0-12-381043-4.00002-7).

17. Whiteley M., Diggle S.P., Greenberg E.P. Progress in and promise of bacterial quorum sensing research. Nature, 2017, 551(7680): 313-320 (doi: 10.1038/nature24624).

18. Schikora A., Schenk S.T., Stein E., Molitor A., Zuccaro A., Kogel K.-H. N-acyl-homoserine lactone confers resistance toward biotrophic and hemibiotrophic pathogens via altered activation of AtMPK6. Plant Physiology, 2011, 157(3): 1407-1418 (doi: 10.1104/pp.111.180604).

19. Schikora A., Schenk S.T., Hartmann A. Beneficial effects of bacteria-plant communication based on quorum sensing molecules of the N-acyl homoserine lactone group. Plant Molecular Biology, 2016, 90(6): 605-612 (doi: 10.1007/s11103-016-0457-8).

20. Бабенко Л.М., Щербатюк, М.М., Мошинець О.В., Косаківська І.В. Ацилгомосеринлактони бактериального походження в біотехнології праймування рослин: досягнення і перспективи використання в аграрному виробництві. Физиология растений и генетика, 2016, 48(6): 63-74.

21. Бабенко Л.М., Мошинец Е.В., Рогальский С.П., Щербатюк Н.Н., Суслова О.С., Косаковская И.В. Влияние предпосевного праймирования $\mathrm{N}$-гексаноил-L-гомосеринлактоном на формирование ризосферной микрофлоры и структуру урожайности Triticum aestivum L. Вісник Харківського національного аграрного університету, 2017, 1: 106-118.

22. Bais H.P., Weir T.L., Perry L.G., Gilroy S., Vivanco J.M. The role of root exudates in rhizosphere interactions with plants and other organisms. Annual Review of Plant Biology, 2006, 57(1): 233266 (doi: 10.1146/annurev.arplant.57.032905.105159).

23. Basu S., Rabara R., Negi S. Towards a better greener future - an alternative strategy using biofertilizers. I: Plant growth promoting bacteria. Plant Gene, 2017, 12: 43-49 (doi: 10.1016/j.plgene.2017.07.004).

24. Ortíz-Castro R., Contreras-Cornejo H.A., Macías-Rodríguez L., López-Bucio J. The role of microbial signals in plant growth and development. Plant Signaling and Behavior, 2009, 4(8): 701712 (doi: 10.4161/psb.4.8.9047).

25. Churchill M.E.A., Chen L. Structural basis of acyl-homoserine lactone-dependent signaling. Chemical Reviews, 2011, 111(1): 68-85 (doi: 10.1021/cr1000817).

26. Gupta G., Kumar A., Verma N. Bacterial homoserine lactones as nanocomposite fertilizer and defense regulator for chickpeas. Environmental Science: Nano, 2019, 6(4): 1-20 (doi: 10.1039/C9EN00199A).

27. Belimov A.A., Dodd I.C., Hontzeas N., Theobald J.C., Safronova V.I., Davies W.J. Rhizosphere bacteria containing 1-aminocyclopropane-1-carboxylate deaminase increase yield of plants grown in drying soil via both local and systemic hormone signalling. New Phytologist, 2009, 181(2): 413- 
423 (doi: 10.1111/j.1469-8137.2008.02657.x).

28. Shi S., Richardson A.E., O'Callaghan M., DeAngelis K.M., Jones E.E., Stewart A., Firestone M.K., Condron L.M. Effects of selected root exudates components on soil bacterial communities. FEMS Microbiology Ecology, 2011, 77(3): 600-610 (doi: 10.1111/j.1574-6941.2011.01150.x).

29. Weller D.M., Raaijmakers J., Gardener B., Thomashow L. Microbial populations responsible for specific soil suppressiveness to plant pathogens. Annual Review of Phytopathology, 2002, 40: 309348 (doi: 10.1146/annurev.phyto.40.030402.110010).

30. Mendes R., Kruijt M., de Bruijn I., Dekkers E., van der Voort M., Schneider J., Piceno Y.M., DeSantis T.Z., Andersen G.L., Bakker P.A.H.M., Raaijmakers J.M. Deciphering the rhizosphere microbiome for disease-suppressive bacteria. Science, 2011, 332(6033): 1097-1100 (doi: 10.1126/science.1203980).

31. Finkel O.M., Castrillo G., Herrera Paredes S., Salas González I., Dangl J.L. Understanding and exploiting plant beneficial microbes. Current Opinion in Plant Biology, 2017, 38: 155-163 (doi: 10.1016/j.pbi.2017.04.018).

32. Kan J., Fang R., Jia Y. Interkingdom signaling in plant-microbe interactions. Science China Life Sciences, 2017, 60(8): 785-796 (doi: 10.1007/s11427-017-9092-3).

33. Lugtenberg B. Life of microbes in the rhizosphere. In: Principles of plant-microbe interactions /B. Lugtenberg (eds.). Springer, Cham, 2015: 7-15 (doi: 10.1007/978-3-319-08575-3_3).

34. Yadav B.K., Akhtar M.S., Panwar J. Rhizospheric plant microbe interactions: key factors to soil fertility and plant nutrition. In: Plant microbes symbiosis: applied facets /N. Arora (eds.). Springer, New Delhi, 2015: 127-145 (doi: 10.1007/978-81-322-2068-8_6).

35. Nadeem S.M., Naveed M., Ahmad M., Zahir Z.A. Rhizosphere bacteria for crop production and improvement of stress tolerance: Mechanisms of action, applications, and future prospects. In: Plant microbes symbiosis: applied facets /N. Arora (eds.). Springer, New Delhi, 2015: 1-36 (doi: 10.1007/978-81-322-2068-8_1).

36. Abhilash P.C., Dubey R.K., Tripathi V., Gupta V.K., Singh H.B. Plant growth-promoting microorganisms for environmental sustainability. Trends in Biotechnology, 2016, 34(11): 847-850 (doi: 10.1016/j.tibtech.2016.05.005).

37. Ma Y., Oliveira R.S., Freitas H., Zhang C. Biochemical and molecular mechanisms of plantmicrobe-metal interactions: relevance for phytoremediation. Frontiers in Plant Science, 2016, 7: 918 (doi: 10.3389/fpls.2016.00918).

38. Ma Y., Rajkumar M., Zhang C., Freitas H. Beneficial role of bacterial endophytes in heavy metal phytoremediation. Journal of Environmental Management, 2016, 174: 14-25 (doi: 10.1016/j.jenvman.2016.02.047).

39. Остапчук М.О., Поліщук І.С., Мазур О.В., Паламарчук В.Д. Мікробіологічні основи агротехнологій. Сільське господарство та лісівництво, 2016, 3: 32-43.

40. Flemming H.C., Wingender J., Szewzyk U., Steinberg P., Rice S.A., Kjelleberg S. Biofilms: an emergent form of bacterial life. Nature Reviews Microbiology, 2016, 14(9): 563-575 (doi: 10.1038/nrmicro.2016.94).

41. Hall-Stoodley L., Costerton J.W., Stoodley P. Bacterial biofilms: from the natural environment to infectious diseases. Nature Reviews Microbiology, 2004, 2(2): 95-108 (doi: 10.1038/nrmicro821).

42. Schuster M., Sexton D.J., Diggle S.P., Greenberg E.P. Acyl-homoserine lactone quorum sensing: from evolution to application. Annual Review of Microbiology, 2013, 67: 43-63 (doi: 10.1146/annurev-micro-092412-155635).

43. Stacy A.R., Diggle S.P., Whiteley M. Rules of engagement: defining bacterial communication. Current Opinion in Microbiology, 2012, 15(2): 155-161 (doi: 10.1016/j.mib.2011.11.007).

44. Schaefer A.L., Greenberg E.P., Colin M.O., Oda Y., Huang J.J., Bittan-Banin G., Peres C.M., Schmidt S., Juhaszova K., Sufrin J.R., Harwood C.S. A new class of homoserine lactone quorumsensing signals. Nature, 2008, 454: 595-599 (doi: 10.1038/nature07088).

45. Yajima A. Recent progress in the chemistry and chemical biology of microbial signaling molecules: quorum-sensing pheromones and microbial hormones. Tetrahedron Letters, 2014, 55(17): $2773-$ 2780 (doi: 10.1016/j.tetlet.2014.03.051).

46. Papenfort K., Bassler B.L. Quorum sensing signal-response systems in Gram-negative bacteria. Nature Reviews Microbiology, 2016, 14(9): 576-588 (doi: 10.1038/nrmicro.2016.89).

47. Schertzer J.W., Boulette M.L., Whiteley M. More than a signal: non-signalling properties of quorum sensing molecules. Trends in Microbiology, 2009, 17(5): 189-195 (doi: 10.1016/j.tim.2009.02.001).

48. Nealson K.H., Platt T., Hastings J.W. Cellular control of the synthesis and activity of the bacterial luminescent system. Journal of Bacteriology, 1970, 104(1): 313-322 (doi: 10.1128/JB.104.1.313322.1970).

49. Schenk S.T., Hernández-Reyes C., Samans B., Stein E., Neumann C., Schikora M., Reichelt M., Mithöfer A., Becker A., Kogel K.H., Schikora A. N-acyl-homoserine lactone primes plants for cell wall reinforcement and induces resistance to bacterial pathogens via the salicylic acid/oxylipin pathway. Plant Cell, 2014, 26(6): 2708-2723 (doi: 10.1105/tpc.114.126763).

50. Fuqua W.C., Wlnans S.C., Greenherg E.P. Quorum sensing in bacteria: the LuxR-Luxl family of cell density-responsive transcriptional regulators. Journal of Bacteriology, 1994, 176(2): 269-275 
(doi: 10.1128/jb.176.2.269-275.1994).

51. Toyofuku M. Bacterial communication through membrane vesicles. Bioscience, Biotechnology, and Biochemistry, 2019, 83(9): 1599-1605 (doi: 10.1080/09168451.2019.1608809).

52. Lopez J.G., Piletska E.V., Whitcombe M.J., Czulak J., Piletsky S.A. Application of molecularly imprinted polymer nanoparticles for degradation of the bacterial autoinducer N-hexanoyl homoserine lactone. Chemical Communications (Cambridge, England), 2019, 55(18): 2664-2667 (doi: $10.1039 / \mathrm{c} 8 \mathrm{cc} 07685 \mathrm{e})$.

53. McBride S.G., Strickland M.S. Quorum sensing modulates microbial efficiency by regulating bacterial investment in nutrient acquisition enzymes. Soil Biology and Biochemistry, 2019, 136: 107514 (doi: 10.1016/j.soilbio.2019.06.010).

54. Tan C.H., Oh H.S., Sheraton V.M., Mancini E., Loo S.C.J., Kjelleberg S., Sloot P.M.A., Rice S.A. Convection and the extracellular matrix dictate inter-and intra-biofilm quorum sensing communication in environmental systems. Environmental Science \& Technology, 2020, 54(11): 6730-6740 (doi: 10.1021/acs.est.0c00716).

55. Rowe S.L., Norman J.S., Friesen M.L. Coercion in the evolution of plant-microbe communication: a perspective. Molecular Plant-Microbe Interactions, 2018, 31(8): 789-794 (doi: 10.1094/MPMI-1117-0276-CR).

56. Calatrava-Morales N., McIntosh M., Soto M. Regulation mediated by $N$-acyl homoserine lactone quorum sensing signals in the Rhizobium-legume symbiosis. Genes, 2018, 9(5): 263 (doi: $10.3390 /$ genes9050263).

57. Zhu H., Sun S.J. Inhibition of bacterial quorum sensing regulated behaviors by Tremella fucifonnis extract. Current Microbiology, 2008, 57(5): 418-422 (doi: 10.1007/s00284-008-9215-8).

58. Sarkar R., Mondal C., Bera R., Chakraborty S., Barik R., Roy P., Kumar A., Yadav K.K., Choudhury J., Chaudhary S.K., Samanta S.K., Karmakar S., Das S., Mukherjee P.K., Mukherjee J., Sen T. Antimicrobial properties of Kalanchoe biossfeldiana: a focus on drug resistance with particular reference to quorum sensing-mediated bacterial biofilm formation. Journal of Pharmacy and Pharmacology, 2015, 67(7): 951-962 (doi: 10.1111/jphp.12397).

59. Foumier-Larente J., Morin M.P., Grenier D. Green tea catechins potentiate the effect of antibiotics and modulate adherence and gene expression in Porphyromonas gingivalis. Archives of Oral Biology, 2016, 65: 35-43 (doi: 10.1016/j.archoralbio.2016.01.014).

60. Ouyang L.J., Li L.M. Effects of an inducible aiiA gene on disease resistance in Eucalyptus urophylla $\times$ Eucalyptus grandis. Transgenic Research, 2016, 25(4): 441-452 (doi: 10.1007/s11248016-9940-x).

61. Teplitski M., Robinson J.B., Bauer W.D. Plants secrete substances that mimic bacterial N-acyl homoserine lactone signal activities and affect population density-dependent behaviors in associated bacteria. Molecular Plant-Microbe Interactions, 2000, 13(6): 637-648 (doi: 10.1094/MPMI.2000.13.6.637).

62. Gao M., Teplitski M., Robinson J.B., Bauer W.D. Production of substances by Medicago truncatula that affect bacterial quorum sensing. Molecular Plant-Microbe Interactions, 2003, 16(9): 827-834 (doi: 10.1094/MPMI.2003.16.9.827).

63. Degrassi G., Devescovi G., Solis R., Steindler L., Venturi V. Oryza sativa rice plants contain molecules that activate different quorum-sensing $\mathrm{N}$-acyl homoserine lactone biosensors and are sensitive to the specific AiiA lactonase. FEMS Microbiology Letters, 2007, 269(2): 213-220 (doi: 10.1111/j.1574-6968.2006.00624.x).

64. Venturi V., Keel C. Signaling in the rhizosphere. Trends in Plant Science, 2016, 21(3): 187-198 (doi: 10.1016/j.tplants.2016.01.005).

65. Pérez-Montaño F., Jiménez-Guerrero I., Contreras Sánchez-Matamoros R., López-Baena F.J., Ollero F.J., Rodríguez-Carvajal M.A., Bellogín R.A., Espuny M.R. Rice and bean AHL-mimic quorum-sensing signals specifically interfere with the capacity to form biofilms by plant-associated bacteria. Research in Microbiology, 2013, 164: 749-760 (doi: 10.1016/j.resmic.2013.04.001).

66. Corral-Lugo A., Daddaoua A., Ortega A., Espinosa-Urgel M., Krell T. Rosmarinic acid is a homoserine lactone mimic produced by plants that activates a bacterial quorum-sensing regulator. Science Signaling, 2016, 9(409): ral (doi: 10.1126/scisignal.aaa8271).

67. Rajamani S., Bauer W.D., Robinson J.B., Farrow J.M. 3rd, Pesci E.C., Teplitski M., Gao M., Sayre R.T., Phillips D.A. The vitamin riboflavin and its derivative lumichrome activate the LasR bacterial quorum-sensing receptor. Molecular Plant-Microbe Interactions, 2008, 21(9): 1184-1192 (doi: 10.1094/MPMI-21-9-1184).

68. Ahumedo M., Díaz A., Vivas-Reyes R. Theoretical and structural analysis of the active site of the transcriptional regulators Las $\mathrm{R}$ and TraR, using molecular docking methodology for identifying potential analogues of acyl homoserine lactones (AHLs) with anti-quorum sensing activity. European Journal of Medicinal Chemistry, 2010, 45(2): 608-615 (doi: 10.1016/j.ejmech.2009.11.004).

69. Keshavan N.D., Chowdhary P.K., Haines D.C., González J.E. L-Canavanine made by Medicago sativa interferes with quorum sensing in Sinorhizobium meliloti. Journal of Bacteriology, 2005, 187(24): 8427-8436 (doi: 10.1128/JB.187.24.8427-8436.2005).

70. Vikram A., Jayaprakasha G.K., Jesudhasan P.R., Pillai S.D., Patil B.S. Suppression of bacterial 
cell-cell signalling, biofilm formation and type III secretion system by citrus flavonoids. Journal of Applied Microbiology, 2010, 109(2): 515-527 (doi: 10.1111/j.1365-2672.2010.04677.x).

71. Vandeputte O.M., Kiendrebeogo M., Rasamiravaka T., Stévigny C., Dutez P., Rojaonson S., Diallo B., Mol A., Baucher M., El Jaziri M. The flavanone naringenin reduces the production of quorum sensing-controlled virulence factors in Pseudomonas aeruginosa PAO1. Microbiology, 2011, 157(7): 2120-2132 (doi: 10.1099/mic.0.049338-0).

72. Nievas F., Vilchez L., Giordano W., Bogino P. Arachis hypogaea L. produces mimic and inhibitory quorum sensing like molecules. Antonie Van Leeuwenhoek, 2017, 110(7): 891-902 (doi: 10.1007/s10482-017-0862-2).

73. Zarkani A.A., Stein E., Röhrich C.R., Schikora M., Evguenieva-Hackenberg E., Degenkolb T., Vilcinskas A., Klug G., Kogel K.H., Schikora A. Homoserine lactones influence the reaction of plants to rhizobia. International Journal of Molecular Sciences, 2013, 14(8): 17122-17146 (doi: 10.3390/ijms140817122).

74. Delalande L., Faure D., Raffoux A., Uroz S., D'Angelo Picard C., Elasri M., Carlier A., Berruyer R., Petit A., Williams P., Dessaux Y. N-hexanoyl-L-homoserine lactone, a mediator of bacterial quorum-sensing regulation, exhibits plant-dependent stability and may be inactivated by germinating Lotus corniculatus seedlings. FEMS Microbiology Ecology, 2005, 52(1): 13-20 (doi: 10.1016/j.femsec.2004.10.005).

75. Ortíz-Castro R., Martínes-Trujillo M., López-Bucio J. N-acyl-L homoserine lactones: a class of bacterial quorum-sensing signals alter post-embryonic root development in Arobidopsis thaliana. Plant, Cell \& Environment, 2008, 31(10): 1497-1509 (doi: 10.1111/j.1365-3040.2008.01863.x).

76. Götz C., Fekete A., Gebefuegi I., Forczek T., Fuksová K., Li X., Englmann M., Gryndler M., Hartmann A., Matucha M., Schmitt-Kopplin P., Schröder P. Uptake, degradation and chiral discrimination of N-acyl-D/L-homoserine lactones by barley (Hordeum vulgaro) and yam bean (Pachyrhizus erosus) plants. Analytical and Bioanalytical Chemistry, 2007, 389(5): 1447-1457 (doi: 10.1007/s00216-007-1579-2).

77. Schuhegger R., Ihring A., Gantner S., Bahnweg G., Knappe C., Vogg G., Hutzler P., Schmid M., Breusegem F., Eberl L., Hartmann A., Langebartels C. Induction of systemic resistance in tomato by N-acyl-L-homoserine lactone-producing rhizosphere bacteria. Plant, Cell \& Environment, 2006, 29(5): 909-918 (doi: 10.1111/j.1365-3040.2005.01471.x).

78. Khan M., Bhargava P., Goel R. Quorum sensing molecules of Rhizobacteria: a trigger for developing systemic resistance in plants. In: Plant growth promoting rhizobacteria for sustainable stress management. Microorganisms for sustainability, vol. 12 /R. Sayyed, N. Arora, M. Reddy (eds.). Springer, Singapore, 2019: 117-138 (doi: 10.1007/978-981-13-6536-2_7).

79. Beckers G.J.M., Jaskiewicz M., Liu Y., Underwood W.R., He S.Y., Zhang S., Conrath U. Mitogen-activated protein kinases 3 and 6 are required for full priming of stress responses in Arabidopsis thaliana. Plant Cell, 2009, 21(3): 944-953 (doi: 10.1105/tpc.108.062158).

80. Breen S., Williams S.J., Winterberg B., Kobe B., Solomon P.S. Wheat PR-1 proteins are targeted by necrotrophic pathogen effectors proteins. Plant Journal, 2016, 88(1): 13-25 (doi: 10.1111/tpj.13228).

81. Breen S., Williams S.J., Outram M., Kobe B., Solomon P.S. Emerging insights into the functions of pathogenesis-related protein 1. Trends in Plant Science, 2017, 22(10): 871-879 (doi: 10.1016/j.tplants.2017.06.013).

82. Prodhan M.Y., Munemasa S., Nahar M.N., Nakamura Y., Murata Y. Guard cell salicylic acid signaling is integrated into abscisic acid signaling via the $\mathrm{Ca}^{2+} / \mathrm{CPK}$-dependent pathway. Plant Physiology, 2018, 178(1): 441-450 (doi: 10.1104/pp.18.00321).

83. Montillet J.L., Leonhardt N., Mondy S., Tranchimand S., Rumeau D., Boudsocq M., Garcia A.V., Douki T., Bigeard J., Lauriure C., Chevalier A., Castresana C., Hirt H. An abscisic acid-independent oxylipin pathway controls stomatal closure and immune defense in Arabidopsis. PLOS Biology, 2013, 11(3): e1001513 (doi: 10.1371/journal.pbio.1001513).

84. Blatt M. $\mathrm{Ca}\left({ }^{2+}\right)$ signalling and control of guard-cell volume in stomata movements. Current Opinion in Plant Biology, 2000, 3(3): 196-204.

85. Negi J., Matsuda O., Nagasawa T., Oba Y., Takahashi H., Kawai-Yamada M., Uchimiya H., Hashimoto M., Iba K. CO2 regulator SLAC1 and its homologues are essential for anion homeostasis in plant cells. Nature, 2008, 452(7186): 483-486 (doi: 10.1038/nature06720).

86. Khokon M.A.R., Salam M.A., Jammes F., Ye W., Hossain M.A., Okuma E., Nakamura Y., Mori I.C., Kwak J.M., Murata Y. MPK9 and MPK12 function in SA-induced stomatal closure in Arabidopsis thaliana. Bioscience, Biotechnology, and Biochemistry, 2017, 81(7): 1394-1400 (doi: 10.1080/09168451.2017.1308244).

87. Song S., Jia Z., Xu J., Zhang Z., Bian Z. N-butyryl-homoserine lactone, a bacterial quorumsensing signaling molecule, induces intracellular calcium elevation in Arabidopsis root cells. Biochemical and Biophysical Research Communications, 2011, 414(2): 355-360 (doi: 10.1016/j.bbrc.2011.09.076).

88. Acharya B.R., Jeon B.W., Zhang W., Assmann S.M. Open Stomata 1 (OST1) is limiting in abscisic acid responses of Arabidopsis guard cells. New Phytologist, 2013, 200(4): 1049-1063 (doi: 
10.1111/nph.12469).

89. Joseph C.M., Phillips D.A. Metabolites from soil bacteria affect plant water relations. Plant Physiology and Biochemistry, 2003, 41(2): 189-192 (doi: 10.1016/S0981-9428(02)00021-9).

90. Liu F., Bian Z., Jia Z., Zhao Q., Song S. The GCR1 and GPA1 participate in promotion of Arabidopsis primary root elongation induced by $\mathrm{N}$-acyl-homoserine lactones, the bacterial quorum-sensing signals. Molecular Plant-Microbe Interactions, 2012, 25(5): 677-683 (doi: 10.1094/MPMI-10-11-0274).

91. Zhao Q., Zhang C., Jia Z., Huang Y., Li H., Song S. Involvement of calmodulin in regulation of primary root elongation by $\mathrm{N}$-3-oxo-hexanoyl homoserine lactone in Arabidopsis thaliana. Frontiers in Plant Science, 2014, 5: 807 (doi: 10.3389/fpls.2014.00807).

92. Jin G., Liu F., Ma H., Hao S., Zhao Q., Bian Z., Jia Z., Song S. Two G-protein-coupledreceptor candidates, Cand 2 and Cand7, are involved in Arabidopsis root growth mediated by the bacterial quorum-sensing signals N-acyl-homoserine lactones. Biochemical and Biophysical Research Communications, 2012, 417(3): 991-995 (doi: 10.1016/j.bbrc.2011.12.066).

93. Mathesius U., Mulders S., Gao M., Teplitski M., Caetano-Anolles G., Rolfe B.G., Bauer W.D. Extensive and specific responses of a eukaryote to bacterial quorum-sensing signals. Proceedings of the National Academy of Sciences, 2003, 100(3): 1444-1449 (doi: 10.1073/pnas.262672599).

94. Lugtenberg B., Kamilova F. Plant-growth-promoting rhizobacteria. Annual Review of Microbiology, 2009, 63(1): 541-556 (doi: 10.1146/annurev.micro.62.081307.162918).

95. Kumar S. Epigenomics of plant's responses to environmental stress. Epigenomes, 2018, 2(1): 6 (doi: 10.3390/epigenomes2010006).

96. Elshakh A.S.A., Anjum S.I., Qiu W., Almoneafy A.A., Li W., Yang Z., Cui Z.-Q., Li B., Sun G.-C., Xie G.-L. Controlling and defence-related mechanisms of Bacillus strains against bacterial leaf blight of rice. Journal of Phytopathology, 2016, 164(7-8): 534-546 (doi: 10.1111/jph.12479).

97. Lareen A., Burton F., Schäfer P. Plant root-microbe communication in shaping root microbiomes. Plant Molecular Biology, 2016, 90(6): 575-587 (doi: 10.1007/s11103-015-0417-8).

98. von Rad U., Klein I., Dobrev P.I., Kottova J., Zazimalova E., Fekete A., Hartmann A., SchmittKopplin P., Durner J. Response of Arabidopsis thaliana to N-hexanoyl-DL-homoserine-lactone, a bacterial quorum sensing molecule produced in the rhizosphere. Planta, 2008, 229(1): 73-85 (doi: 10.1007/s00425-008-0811-4).

99. Zhao Q., Li M., Jia Z., Liu F., Ma H., Huang Y., Song S. AtMYB44 positively regulates the enhanced elongation of primary roots induced by N-3-oxo-hexanoyl-homoserine lactone in Arabidopsis thaliana. Molecular Plant-Microbe Interactions, 2016, 29(10): 774-785 (doi: 10.1094/MPMI-03-16-0063-R).

100. Pang Y., Liu X., Ma Y., Chernin L., Berg G., Gao K. Induction of systemic resistance, root colonisation and biocontrol activities of the rhizospheric strain of Serratia plymuthica are dependent on N-acyl homoserine lactones. European Journal of Plant Pathology, 2008, 124(2): 261-268 (doi: 10.1007/s10658-008-9411-1).

101. Shrestha A., Schikora A. AHL-priming for enhanced resistance as a tool in sustainable agriculture. FEMS Microbiology Ecology, 2020, 96(12): fiaa226 (doi: 10.1093/femsec/fiaa226).

${ }^{1}$ Институт ботаники им. Н.Г. Холодного НАН Украины, 01004 Украина, г. Киев, ул. Терещенковская, 2, e-mail: lilia.babenko@gmail.com $₫$, katerynaromanenko4@gmail.com;

${ }^{2}$ Институт молекулярной биологии и генетики

НАН Украины,

03143 Украина, г. Киев, ул. Академика Заболотного, 150,

e-mail: olgaungin@gmail.com;

${ }^{3}$ Киевский национальный университет технологий

и дизайна (КНУТД),

01011 Украина, г. Киев, ул. Немировича-Данченка, 2,

e-mail: irynakosakivska@gmail.com

Sel'skokhozyaistvennaya biologiya [Agricultural Biology], 2021, V. 56, № 1, pp. 3-19

\title{
ACYL-HOMOSERINE LACTONES FOR CROP PRODUCTION AND STRESS TOLERANCE OF AGRICULTURAL PLANTS (review)
}

\author{
L.M. Babenko ${ }^{\boxplus}$, K.O. Romanenko ${ }^{1}$, O.S. Iungin ${ }^{2,}, 3$, I.V. Kosakovska ${ }^{1}$
}

\footnotetext{
${ }^{1}$ Kholodny Institute of Botany of the National Academy of Sciences of Ukraine, 2, Tereschenkivska Str., Kyiv, 01004 Ukraine, e-mail lilia.babenko@gmail.com ( $₫$ corresponding author), katerynaromanenko4@gmail.com;

${ }^{2}$ Institute of Molecular Biology and Genetics of the National Academy of Sciences of Ukraine, 150, Akademika Zabolotnogo Str., Kyiv, 03143 Ukraine, e-mail olgaungin@gmail.com;
} 
${ }^{3}$ Kyiv National University of Technologies and Design (KNUTD), 2, Nemyrovycha-Danchenka Str., Kyiv, 01011 Ukraine, e-mail irynakosakivska@gmail.com

ORCID:

Babenko L.M. orcid.org/0000-0001-5391-9203

Romanenko K.O. orcid.org/0000-0003-0456-4412

Iungin O.S. orcid.org/0000-0001-8876-6075

The authors declare no conflict of interests

Acknowledgements:

The work has been carried out within the framework of the project № 0120 U102936 "Development of innovative biotechnology for increasing the stability and productivity of cereals based on a complex of signaling molecules of plant and bacterial origin for environmental protection and restoration" (2020-2024) funded by the National Academy of Sciences of Ukraine.

Received June 18, 2020

doi: 10.15389/agrobiology.2021.1.3eng

\section{Abstract}

Acyl homoserine lactones (AHL) are a class of mediator molecules coordinating cell activity in the gram-negative bacteria population. AHLs synchronize individual genomes due to which bacterial populations function as a multicellular organism. AHLs provide a remote signaling between bacteria colonizing the phytosphere that enables the bacterial population to respond to external influences and establish symbiotic or antagonistic relationships with the host plant (A.R. Stacy et al., 2018; A. Shrestha et al., 2020). Autoreception of quantitative parameters of the bacterial population is called "quorum sensing" (QS) (R.G. Abisado et al., 2018). QS systems form autoinducer signaling molecules that easily penetrate from cells into the environment and back into the cell (M.B. Miller et al., 2001; B. Bassler, 2002). QS systems play a key role in the regulation of metabolic and physiological processes in a bacterial cell (M. Frederix et al., 2011; M. Whiteley et al., 2017). Bacterial signaling is perceived by eukaryotes, which form a symbiosis with microbial communities (A. Schenk et al., 2015; L.M. Babenko et al., 2016, 2017). Plant growth and development, nutrients assimilation, and stress resistance are largely determined by the pattern of this interaction (H.P. Bais et al., 2006; R. Ortíz-Castro et al., 2009; S. Basu et al., 2017). In the plant, bacterial signaling is controlled by the quorum quenching (QQ) system (N. Calatrava-Morales et al., 2018), whose mechanism of action is to suppress AHL synthesis by plant metabolites, compete with AHL for binding to receptor proteins, and repression of QS-controlled genes (H. Zhu et al., 2008; R. Sarkar et al., 2015). However, to date, the molecular mechanisms by which plants respond to bacterial signaling are not fully understood. Individual metabolites of AHL signaling have been characterized, but their role in the chemical interaction of partners in most cases requires further study. It has been shown that the QS phenomenon and its participants are involved in the regulation of prokaryotic-eukaryotic interactions, including the formation of biofilms, the synthesis of phytohormones, the transfer of plasmids, the production of virulence factors, bioluminescence, sporulation, and the formation of nodules (L.M. Babenko et al., 2017). Differences in the structure of molecules ensure that bacteria recognize their own AHL and separate foreign ones. The transfer of AHL from a bacterium to a host plant is carried out by means of membrane vesicles (M. Toyofuku, 2019). In recent years, there has been an active study of genetics, genomics, biochemistry, and signaling diversity of QS molecules. The regulation of the functions of the rhizosphere, the most dynamic site of interaction between the plant and the associated microflora with the participation of AHL, is of particular importance in the development of new biotechnological approaches aimed at increasing the yield and stress resistance of agricultural crops. One of the effective technologies for increasing resistance to biotic and abiotic stresses is pre-sowing treatment (priming) of seeds (A. Shrestha et al., 2020). Both direct (on plants) and indirect (on rhizosphere microflora) effects of AHL priming was established (O.V. Moshynets et al., 2019). AHL induce an increase of growth, of photosynthetic pigments content, as well as cause changes in the ratio of phytohormones in organs and tissues, affect the formation of defense mechanisms, which increases the productivity of agricultural crops (A. Schikora, S.T. Schenk, 2016; A. Shrestha et al., 2020). AHL meet the requirements of intensive organic farming, they are considered as promising ecological phytostimulants and phytomodulators capable of safely increasing the quantity and quality of agricultural products.

Keywords: acyl-homoserine lactones (AHL), quorum sensing (QS), quorum quenching (QQ), plant-microbial signaling, AHL-priming, AHL-mimicry, phytostimulants, phytomodulators, stress resistance. 